\section{KẾT LUẬN}

Mô hình được xây dựng. Mô hình được xây dựng trong phần mềm MS Microsoft Excel với cẩu trúc mô hình bao gồm các trang tính toán các tham số đầu ra cho 2 viễn cảnh không có RUX và có RUX cho phép phân tích tác động ngân sách của RUX trong điều trị xơ tủy nguyên phát, đánh giá được tác động hiệu quả điều trị giữa hai viễn cảnh điều trị và cho phép cập nhật các tham số đầu vào đề thu được kết quả cập nhật nhất cho từng thời điểm nghiên cứu nhất định.

\section{TÀI LIÊU THAM KHẢO}

1. Tefferi A. Primary myelofibrosis: 2021 update on diagnosis, risk-stratification and management. American journal of hematology. 2021;96(1):145-162.

2. Harrison $C N$, Vannucchi AM, Kiladjian J-J, et al. Long-term findings from COMFORT-II, a phase
3 study of ruxolitinib vs best available therapy for myelofibrosis. Leukemia. 2016;30(8):1701-1707.

3. Cervantes F, Vannucchi AM, Kiladjian JJ, et al. Three-year efficacy, safety, and survival findings from COMFORT-II, a phase 3 study comparing ruxolitinib with best available therapy for myelofibrosis. Blood. 2013;122(25):4047-4053.

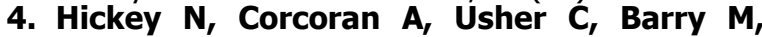
McCullagh L. 2017; A462. Available at. Accessed 9, 20.

5. Marshall DA, Douglas PR, Drummond MF, et al. Guidelines for conducting pharmaceutical budget impact analyses for submission to public drug plans in Canada. Pharmacoeconomics. 2008;26(6):477-495.

6. Gómez-Casares MT, Hernández-Boluda JC, Jiménez-Velasco A, et al. Cost-effectiveness of Ruxolitinib vs Best Available Therapy in the Treatment of Myelofibrosis in Spain. Journal of Health Economics and Outcomes Research. 2017;5(2):162-174.

\title{
CHI PHÍ ĐIỀU TRI TRỰC TIẾP BÊ̂NH LOẠN SẢN PHẾ QUẢN PHỔI TẠI BỆNH VIỆN NHI TRUNG ƯƠNG NĂM 2020
}

\section{TÓM TẮT}

Muc tiêu: Mô tả chi phí điều tri trực tiếp cho y tế và các yếu tố liên quan trong điều trị trẻ sơ sinh mắc chứng loạn sản phế quản phổi tại Bệnh viện Nhi Trung ương trong năm 2020. Phương pháp nghiên cứu: Mô tả cắt ngang, phân tích định lượng dữ liệu hồi cứu của tất cả trẻ sơ sinh điều trị chứng loạn sản phế quản phổi tại Bệnh viện trong 2020. Kết quả: Trong tổng 116 đối tượng nghiên cứu, nam là chủ yếu với 63,8\%, tỷ lệ trẻ đẻ non <28 tuân là $59,8 \%$. Tổng chi phí trực tiếp cho y tế trung bình năm/1 trẻ là 3292,5 $\pm 3043,8$ USD. Chi phí này tỷ lệ thuận với cân nặng khi sinh và thời gian nằm viện. Kết luẩn: Chi phí ở Việt Nam thấp hơn đáng kể so với chi phí quốc tế ở các nghiên cứu tương tự. Chính sách bảo hiểm y tế miến phí cho trẻ < 6 tuổi và tỷ lệ đồng chi trả < $20 \%$ làm giảm đáng kể gánh năng kinh tế của gia đình có trẻ phải điều trị chứng lìạn sản phế quản phổi và hoàn toàn nằm trong khả năng chi trả.

Tư khóa: Chi phí, chứng loạn sản phế quản phổi, trẻ sơ sinh, Bệnh viện Nhi Trung ương

\section{SUMMARY}

${ }^{1}$ Bệnh viện Nhi Trung ương

2Trường Đại học Y Hà Nội

${ }^{3}$ Vu Kế hoạch Tài chính - Bô Y tế

Chịu trách nhiệm chính: Trần Thị Thu Trang

Email: tranthithutrang33@gmail.com

Ngày nhận bài: 2.6.2021

Ngày phản biện khoa học: 2.8.2021

Ngày duyệt bài: 11.8.2021
Trần Thị Thu Trang ${ }^{1}$, Trần Minh Điển ${ }^{1}$, Phạm Huy Tuấn Kiệt ${ }^{2}$, Vũ Xuân Hoàng ${ }^{3}$

\section{DIRECT TREATMENT COST OF BRONCHOPULMONARY DYSPLASIA AT VIETNAM NATIONAL CHILDREN'S HOSPITAL IN 2020}

Objectives: To describe direct medical cost and related factors for treatment of bronchopulmonary dysplasia (BPD) at the Vietnam National Children's Hospital in 2020. Methodology: Cross-sectional study, quantitative analysis on medical and financial records of all premature infants with bronchopulmonary dysplasia, treated at the National Children's Hospital in 2020. Findings: Among 116 premature infants with bronchopulmonary dysplasia, males in majority with $63,8 \%$, premature $<28$ weeks with $59,8 \%$. The average annual total direct medical cost per infant was $3292.5 \pm 3043.8$ USD. Value of cost is proportional to birth weight and length of stay. Conclusion: Cost in Vietnam is significantly comparing with similar international studies. Policy of free health insurance for children $<6$ year olds and co-payment of $<20 \%$ reduced the financial burden of families having premature infant with bronchopulmonary dysplasia largely. It was totally affordable in Vietnam.

Keywords: Cost, bronchopulmonary dysplasia, infants, Vietnam National Children's Hospital

\section{I. ĐĂT VẤN ĐỀ}

Theo Tổ chức $Y$ tế Thế giới (WHO), cứ mỗi năm lại có 15 triệu trẻ sinh non toàn cầu. Đây được cho là nguyền nhân tử vong hàng đầu ở trẻ em dưới 5 tuổi ở các nước có thu nhập thấp và trung bình [1]. Bệnh lý lâm sàng phổ biến nhất ở 
trẻ sinh non là loạn sản phế quản phổi (BPD)[2],[3]. Trẻ mắc chứng loạn sản phế quản phổi thướng phải nhập viện nhiều lần, sử dụng các dịch vụ y tế tăng cường và dẫn đến gia tăng gánh nặng kinh tế của gia đình [4]. Một nghiên cứu tại Hoa Kỳ, xuất bản năm 2020 cho thấy chi phí điều trị trung bình của 1 trẻ bị mắc loạn sản phế quản phổi trong năm đầu tiên có thể lển đến 377.871 USD[5]. Một nghiên cứu khác tại Tây Ban Nha, xuất bản năm 2017 cho thấy chi phí điều trị trong 2 năm đầu đời của một trẻ sinh non mắc chứng loạn sản phế quản phổi và không có biến chứng khác liên quan đến sinh non giao động từ 45.049,81 đến $118.760,43$ Euro, biến động theo cân nặng khi sinh và tuổi thai [6]. Y vằn ở Việt Nam có rất ít nghiên cứu tương tự mặc dù chi phí điều trị cho nhóm bệnh nhân này là rất lớn. Do vậy, chúng tôi thực hiện nghiên cứu "Chi phí điều trị trực tiếp bệnh loạn sản phế quản phổi tại Bệnh viện Nhi Trung ương năm 2020" với mục tiêu phân tích chi phí và xác định các yếu tố liên quan.

\section{II. ĐỐI TƯợNG VÀ PHƯƠNG PHÁP NGHIÊN CỨU}

Đây là nghiên cứu mô tả cắt ngang, phân tích định lượng dữ liệu hồi cứu. Vật liệu nghiên cứu là hồ sơ bệnh án điện tử của tất cả trẻ sơ sinh mắc chứng loạn sản phế quản phổi được điều trị tại Bệnh viện Nhi Trung ương Việt Nam, có thời gian nhập viện sau ngày $01 / 01 / 2020$ và thời xuất viện trước 31/12/2020.

Biến số nghiên cứu gồm thông tin hành chính, cân nặng và tuổi thai của trẻ khi sinh, thông tin lâm sàng của đợt điều trị và thông tin các chi phí điều trị trực tiếp cho y tế của đợt điều trị. Thông tin chi phí là tổng chi phí trong năm nghiên cứu/ 1 trẻ. Các chi phí trực tiếp cho y tế là phí chi cho giường bệnh, xét nghiệm, chuẩn đoấn hình ảnh, thăm dò chức năng, thuốc, máu, phẫu thuật/ thủ thuật, vật tư y tế và chi phí khác. Mỗi chi phí gồm tổng chi phí từ phần được BHYT chi trả và phần bệnh nhân tự trả. Đây cũng là hạn chế của nghiên cứu vì không theo dõi dọc trẻ nhiều năm để xác định chi phí theo đợt điều trị và theo từng năm sau sinh.

Nghiên cứu được phê duyệt trong khuôn khổ phê duyệt đề cương luật văn thạc sĩ YTCC quốc tế của Viện Đào tạo $Y$ học Dự phòng và $Y$ tế công cộng - Trường Đại học Y Hà Nội. Nghiên cứu được Bệnh viện Nhi Trung ương chấp thuận cho thực hiện. Dữ liệu được trích xuất không có thông tin cá nhân, cững như thông tin có thể xác định danh tính bệnh nhi và gia đình.

\section{KẾT QUẢ NGHIÊN CỨU}

3.1. Đặc điểm của đôii tượng nghiên cứu Bảng sau mô tả đặc điểm chung của đối tượng nghiên cứu:

Bảng 3.5: Đặc điểm của đôî tượng nghiên cứu (n=116)

\begin{tabular}{|c|c|c|}
\hline Đặc điểm & $\begin{array}{c}\text { Số lương } \\
\text { (n) }\end{array}$ & $\begin{array}{c}\text { Tỉ lêe } \\
\text { (\%) }\end{array}$ \\
\hline \multicolumn{2}{|c|}{ Giới tính trẻ } \\
\hline Nam & 74 & $63,8 \%$ \\
\hline Nữ & 42 & $36,2 \%$ \\
\hline Khu vực sinh sống \\
\hline Hà Nội & 24 & $20,7 \%$ \\
\hline Đồng bằng sồng Hồng & 36 & $31,0 \%$ \\
\hline $\begin{array}{c}\text { Trung du và miền núi } \\
\text { phía Bắc }\end{array}$ & 27 & $23,3 \%$ \\
\hline $\begin{array}{c}\text { Bắc Trung Bồ và Duyên } \\
\text { hải miền Trung }\end{array}$ & 29 & $25,0 \%$ \\
\hline
\end{tabular}

\begin{tabular}{|c|c|c|}
\hline \multicolumn{3}{|c|}{ Tuối thai khi sinh } \\
\hline 32-36 tuần & 8 & $7,1 \%$ \\
\hline 28-31 tuần & 37 & $33,0 \%$ \\
\hline$<28$ tuần & 67 & $59,8 \%$ \\
\hline \multicolumn{3}{|c|}{ Cân nặng khi sinh } \\
\hline$\geq 2500 \mathrm{~g}$ & 6 & $5,4 \%$ \\
\hline $1500-2499 \mathrm{~g}$ & 38 & $34,2 \%$ \\
\hline $1000-1499 \mathrm{~g}$ & 45 & $40,5 \%$ \\
\hline$<1000 \mathrm{~g}$ & 22 & $19,8 \%$ \\
\hline \multicolumn{3}{|c|}{ Thời gian nằm viện } \\
\hline$<14$ ngày & 32 & $27,6 \%$ \\
\hline $15-30$ ngày & 23 & $19,8 \%$ \\
\hline $31-60$ ngày & 32 & $27,6 \%$ \\
\hline$>60$ ngày & 29 & $25,0 \%$ \\
\hline \multicolumn{3}{|c|}{ Chuyến tuyến } \\
\hline Trái tuyến & 19 & $16,4 \%$ \\
\hline Đúng tuyến & 97 & $83,6 \%$ \\
\hline
\end{tabular}

Trong 116 trẻ sơ sinh mắc chứng loạn sản phế quản phổi, tỷ lệ trẻ là nam với $63,8 \%$ cao hơn nữ với 36,2\%. 51,7\% trẻ đến từ Đồng bằng sông Hồng; số trẻ còn lại phân bổ tương đối đều cho Trung du và miến núi phía Bắc, Bắc Trung bộ và Duyên hải miền Trung. $59,8 \%$ trẻ có tuổi thai khi sinh $<28$ tuân. $60,3 \%$ trẻ có cân nặng khi sinh $<1500$ g. $53,6 \%$ trẻ có thời gian nằm viện < 1tháng. 95,7\% trẻ có thẻ BHYT và $83,6 \%$ trẻ được chuyến đến Bệnh viện Nhi Trung ương đúng tuyến.

3.2. Chi phí trực tiếp cho y tế điêu trị hội chứng loạn sản phế quản phổi

Bảng sau xác định tổng chi phí trực tiếp cho y tế trong năm nghiên cứu / 1 trẻ và các câu phân của chi phí

Bảng 3.6: Chi phí trực tiếp cho y tê điều trị hội chứng loạn sản phế quản phổi trong năm nghiên cứu của đối tượng nghiên cứu 
$(n=116)$

(Đơn vị: USD, tỉ giá quy đổi năm 2020: 1 USD=)

\begin{tabular}{|c|c|c|c|}
\hline Chi phí & $\begin{array}{c}\text { Trung } \\
\text { bình }\end{array}$ & SD & $\begin{array}{c}\text { Trung } \\
\text { vị }\end{array}$ \\
\hline Tống chi phí & 3292,5 & 3043,8 & 2346.0 \\
\hline $\begin{array}{c}\text { Chi phí giường } \\
\text { bệnh }\end{array}$ & 1380,8 & 1220,9 & 964,8 \\
\hline $\begin{array}{c}\text { Chi phí xét } \\
\text { nghiệm }\end{array}$ & 4310,2 & 4890,6 & 2992,6 \\
\hline $\begin{array}{c}\text { Chi phí chuẩn } \\
\text { đoán hình aánh }\end{array}$ & 43,5 & 47,5 & 27.6 \\
\hline $\begin{array}{c}\text { Chi phí thăm } \\
\text { dò chức năng }\end{array}$ & 5,06 & 7,0 & 0 \\
\hline Chi phí thuốc & 423,99 & 577,7 & 199,0 \\
\hline Chi phí máu & 21,49 & 25,2 & 10,9 \\
\hline $\begin{array}{c}\text { Chi phí phâuu } \\
\text { thuật/ thú } \\
\text { thuật }\end{array}$ & 737,2 & 912,4 & 338,7 \\
\hline $\begin{array}{c}\text { Chi phí vật tư } \\
\text { y tế }\end{array}$ & 209,14 & 184,0 & 149,4 \\
\hline $\begin{array}{c}\text { Chi phí dịch vụ } \\
\text { khác }\end{array}$ & 39,7 & 43,1 & 27,1 \\
\hline
\end{tabular}

Tổng chi phí trung bình trong năm nghiên cứu điều trị 1 trẻ mắc chứng loạn sản phế quản phổi là 3292,5 USD. Gía trị tối đa là 4392 USD, trong khi giá trị tối thiểu chỉ là 10 USD. Sự biến thiên là rất lớn với $S D=3043,8$ USD. Chi phí phổ biến, với trung vị là 2346 USD. Phần lớn chi phí là cho xét nghiệm, cao cả ở trung bình cũng như trung vị, tiếp đến là chi phí giường bệnh, chi phí phẫu thuật, thủ thuật, chi phí thuốc và chi phí vật tư y tế. Thấp nhất là chi phí chuẩn đoán hình ảnh, chi phí máu và các dịch vụ không xác định khác.

3.2. Các yếu tố liên quan đến chi phí trực tiếp cho y tế điêuu trị hội chứng loạn sản phế quản phổi

Bảng sau tổng hợp kêt quả kiểm định thống kê tổng chi phí trung bình trực tiếp cho y tế điêu trị hội chứng loạn sản phế quản phổi theo các yếu tố liên quan:

Bảng 3.7: Kiểm định thống kê tổng chi phí trung bình trực tiếp cho y tế điều trị bệnh loạn sản phế quản phổi

(Đơn vị tính: USD)

\begin{tabular}{|c|c|c|c|}
\hline $\begin{array}{c}\text { Yếu tố } \\
\text { liên quaan }\end{array}$ & $\begin{array}{c}\text { Trung bình } \\
\pm 95 \% \mathrm{CI}\end{array}$ & $\begin{array}{c}\text { Trung } \\
\text { vị }\end{array}$ & p* \\
\hline \multicolumn{4}{|c|}{ Giới tính } \\
\hline Nam & $\begin{array}{c}2964,1 \pm \\
635,9\end{array}$ & 1868,7 & \multirow{2}{*}{0,164} \\
\hline Nũ̃ & $\begin{array}{c}3866,2 \pm \\
1082,8\end{array}$ & 4476,9 & \\
\hline \multicolumn{4}{|c|}{ Khu vực sinh sống } \\
\hline Hà Nội & $\begin{array}{l}4236,6 \pm \\
1702,6\end{array}$ & 5212,7 & 0,437 \\
\hline
\end{tabular}

\begin{tabular}{|c|c|c|c|}
\hline $\begin{array}{l}\text { Đồng bằng } \\
\text { sông Hồng }\end{array}$ & $\begin{array}{c}3603,4 \pm \\
1035,4\end{array}$ & 3130,9 & \\
\hline $\begin{array}{l}\text { Trung du } \\
\text { miền núi } \\
\text { phía Bắc }\end{array}$ & $\begin{array}{c}3028,4 \pm \\
1126,6\end{array}$ & 1718,8 & \\
\hline $\begin{array}{c}\text { Bắc Trung } \\
\text { Bộ }\end{array}$ & $\begin{array}{c}2386.2 \pm \\
775,2\end{array}$ & 1518,0 & \\
\hline \multicolumn{4}{|c|}{ Tuối thai khi sinh } \\
\hline 32-36 tuần & $\begin{array}{c}2458,6 \pm \\
1833,0\end{array}$ & 2660,7 & \multirow{3}{*}{0,638} \\
\hline 28-31 tuần & $\begin{array}{c}3457,2 \pm \\
959,7\end{array}$ & 3239,3 & \\
\hline <28 tuân & $\begin{array}{c}3242,8 \pm \\
748,7\end{array}$ & 1784,9 & \\
\hline \multicolumn{4}{|c|}{ Cân nặng khi sinh } \\
\hline$\geq 2500 \mathrm{~g}$ & $\begin{array}{c}5547,7 \pm \\
4653,6\end{array}$ & 6638,4 & \multirow{4}{*}{$<0,001$} \\
\hline $\begin{array}{l}1500- \\
2499 g\end{array}$ & $\begin{array}{c}2240,6 \pm \\
768,5\end{array}$ & 991,5 & \\
\hline $\begin{array}{l}1000- \\
1499 \mathrm{~g}\end{array}$ & $\begin{array}{c}2848.8 \pm \\
831,7\end{array}$ & 2064,8 & \\
\hline$<1000 \mathrm{~g}$ & $\begin{array}{c}5262,2 \pm \\
1165,6\end{array}$ & 5527,3 & \\
\hline \multicolumn{4}{|c|}{ Thời gian nằm viện } \\
\hline$<14$ ngày & $483,4 \pm 172,1$ & 315,5 & \multirow{4}{*}{$<0,001$} \\
\hline $\begin{array}{c}15-30 \\
\text { ngày }\end{array}$ & $\begin{array}{c}1114,4 \pm \\
232,2\end{array}$ & 906,5 & \\
\hline $\begin{array}{c}31-60 \\
\text { ngày }\end{array}$ & $\begin{array}{c}4314,2 \pm \\
534,3\end{array}$ & 4477,4 & \\
\hline > 60 ngày & $\begin{array}{c}6887,0 \pm \\
879,5\end{array}$ & 6131,8 & \\
\hline
\end{tabular}

*Kiểm định Kruskal-Wallis

Do tổng chi phí phân bố không chuẩn, nghiên cứu kiểm định phi tham số theo Kruskal-Wallis sự khác biệt theo giới tính, khu vực sinh sống, tuổi thai khi sinh, cân nặng khi sinh và thời gian nằm viện. Với $p>0,005$, sự khác biệt về tổng chi phí trung bình năm trực tiếp cho y tế không có sự khác biệt giữa nam và nữ, giữa các khu vực của gia đình trẻ và giữa các nhóm tuổi thai. Trẻ có cân nặng càng thấp càng có chi phí điều trị càng cao và trẻ có thời gian nằm viện càng dài cũng có chi phí điều trị càng cao. Sự khác biệt này rất có ý nghĩa thống kê với $p<0,001$.

\section{BÀN LUẬN}

Chứng loạn sản phế quản phổi là một bệnh lý nghiêm trọng nguy hiểm ở trẻ sơ sinh sinh non thiếu cân. Nghiên cứu của chúng tôi thực hiện trên 116 hồ sơ bệnh nhi mắc loạn sản phế quản phổi cho thấy tỷ lệ các trẻ đẻ non <28 tuân cao $(59,8 \%)$ và gần $95 \%$ trẻ dưới $2500 \mathrm{~g}$. Tổng chi phí trực tiếp cho y tế trung bình năm nghiên cứu điều trị cho 1 trẻ là $3292,5 \pm 3043,8$ USD. Cấu phần chi phí có tỷ trọng cao nhất là chi phí cho 
xét nghiệm, tiếp đến là cho giường bệnh, phẫu thuật, thủ thuật, thuốc và vật tư y tế. Một nghiên cứu thuần tập hồi cứu cứu tại Mỹ về các ca sinh non ở California từ năm 2008 đến năm 2011, kết hợp thông tin giữa giấy chứng sinh, hồ sơ xuất viện và dữ liệu lâm sàng trên 2696 trẻ loạn sản phế quản phổi cho kết quả chi phí nằm viện trung bình trong năm đầu tiên là 377.871 USD cho mỗi trẻ sơ sinh[5], cao hơn 100 lần số tuyệt đối trong 2020 của chúng tôi. Nghiên cứu dựa trên số liệu của Bộ Y tế Tây Ban Nha trên 2628 trẻ sinh non mắc chứng loạn sản phế quản phổi năm 2013 cho thấy chi phí cho 2 năm đâu đời của một đứa trẻ sinh non mắc chứng loạn sản phế quản phổi và không có biến chứng nào khác liên quan đến sinh non là từ 45.049,81 đến $118.760,43$ Euro[6], cao hơn 15-30 lần số tuyệt đối trong 2020 của chúng tôi. Hay nghiên cứu thuần tập hồi cứu dữ liệu của 773 bệnh nhi bị biến chứng hô hấp do sinh non ở Quebec/ Canada từ năm 1983 đến năm 1992 cho thấy chi phí điều trị trung bình năm là 13.472 Canada Đôla[7], cũng cao hơn nhiều lần số tuyệt đối trong 2020 của chúng tôi. Không chỉ ở Việt Nam, trẻ sinh non mắc chứng loạn sản phế quản phổi phải được điều trị bệnh viện lâu ngày, không chỉ tác động đến sức khỏe của trẻ mà còn là gánh nặng tài chính của BHYT và gia đình [4].

Trong nghiên cứu của chúng tôi, trẻ có cân nặng khi sinh càng thấp, và thời gian nằm viện càng dài thì chi phí điêu trị tăng lên rõ rệt. Phát hiện này tương đồng với các nghiên cứu trước đó tại Mỹ, Tây Ba Nha và Canada [4],[5],[6]. Trẻ sơ sinh mắc chứng loạn sản phế quản phổi thường phải điêuu trị nội trú tới 4 tháng, trường hợp nặng có khi hơn 1 năm trong Khoa Điêu trị tích cực, trước khi xuất viện về nhà lần đầu tiên. Thời gian lưu trú trong Khoa Hồi sức tích cực kéo dài làm gia tăng tiếp xúc với các nhiễm trùng bệnh viện, dẫn tới kéo dài và tăng chi phí điều trị[8]. Trong nghiên cứu tại California (2020) và Tây Ba Nha (2017), các tác giả đưa ra yếu tố tuần thai sinh khi sinh của trẻ có ảnh hưởng đến chi phí điều trị[[5], [6]. Kiểm định trong nghiên cứu của chúng tôi lại chưa thấy được sự khác biệt của chi phí trong các nhóm tuẩn thai khi sinh. Điều này có thể do cỡ mẫu hạn chế cũng dữ liệu chi phí là của năm nghiên cứu thay vì năm sau sinh.

Kết quả được trình bày trong nghiên cứu này cho thấy chi phí y tế trung bình cho trẻ sinh non mắc chứng loạn sản phế quản phổi ở Việt Nam là đáng kể đối với hệ thống y tế nói chung. Từ đó khuyến khích các gia đình tham gia chính sách bảo hiểm y tế quốc gia, nhận tư vấn từ cơ sở chăm sóc y tế, nhằm giảm gánh nặng kinh tế sau này.

\section{KẾT LUÂ̂N VÀ KHUYẾN NGH!}

Nghiên cứu thực hiện trên 116 hồ sơ bệnh nhi mắc chứng loạn sản phế quản phổi trong 2020 cho thấy tổng chi phí trực tiếp cho y tế trung bình năm trên 1 trẻ là 3292,5 \pm 3043,8 USD. Chí phí tỷ lệ thuận với cân nặng khi sinh và thời gian nằm viện của trẻ. Số tuyệt đối của nghiên cứu thấp hớn đáng kể so với chi phí cho điều trị trẻ sơ sinh mắc chứng loạn phế quản phổi ở Hoa Kỳ, Tây Ba Nha và Canada trong các nghiên cứu tương tự. Chi phí ở Việt Nam cao hơn không nhiêu so với GPD/ người (2785,7 USD - 2020). Với chính sách tất cả trẻ $<6$ tuổi được BHYT miễn phí và chỉ phải đồng chi trả $<20 \%$, thì gánh nặng kinh tế đối với gia đình có trẻ sơ sinh mắc chứng loạn ản phế quản phổi là không cao và trong khả năng chi trả.

Nghiên cứu của chúng tôi là một trong những nghiên cứu đầu tiên phân tích chí phí theo các yếu tố lâm sàng tại Bệnh viện Nhi Trung ương và mong muốn thúc đẩy xu hướng này trong thời gian tới tại Bệnh viện.

\section{TÀI LIỆ THAM KHẢO}

1. World Health Organization (2018). Preterm birth.<https://www.who.int/en/news-room/factsheets/detail/preterm-birth>, accessed: $01 / 01 / 2021$.

2. Jensen E.A. và Schmidt B. (2014). Epidemiology of bronchopulmonary dysplasia.Birt Defects Res A Clin Mol Teratol, 100(3), 145-157.

3. Baker C.D. và Alvira C.M. (2014). Disrupted lung development and bronchopulmonary dysplasia: opportunities for lung repair and regeneration. Curr Opin Pediatr, 26(3), 306-314.

4. Smith V.C., Zupancic J.A.F., McCormick M.C. và cộng sứ. (2004). Rehospitalization in the first year of life among infants with bronchopulmonary dysplasia.J Pediatr, 144(6), 799-803.

5. Lapcharoensap $\mathbf{W} .$, Bennett M.V., Xu X. và cộng sự. (2020). Hospitalization costs associated with bronchopulmonary dysplasia in the first year of life. J Perinatol Off J Calif Perinat Assoc, 40(1), $130-137$.

6. Álvarez-Fuente M., Arruza L., Muro M. và cộng sự. (2017). The economic impact of prematurity and bronchopulmonary dysplasia. Eur J Pediatr, 176(12), 1587-1593.

7. Landry J.S., Croitoru D., Jin Y. và cộng sự.(2012). Health care utilization by preterm infants with respiratory complications in Quebec.Can Respir J, 19(4), 255-260.

8. Merritt T.A., Pillers D., và Prows S.L. (2003). Early NICU discharge of very low birth weight infants: a critical review and analysis. Semin Neonatol SN, 8(2), 95-115. 